\title{
A Simple and Green Synthesis of Tetrahydrobenzo[ $\alpha]$-xanthen-11-one Using PEG-400 as Efficient and Recyclable Reaction Media
}

\author{
Nana V. Shitole, S. B. Sapkal, Bapurao B. Shingate, and Murlidhar S. Shingare* \\ Department of Chemistry, Dr. Babasaheb Ambedkar Marathwada University, Auranagabad-431 004, MS, India \\ *E-mail: msshingare11@gmail.com \\ Received October 5, 2010, Accepted November 13, 2010
}

Key Words: Xanthenes, Aromatic aldehyde, PEG-400, Green chemistry

Multicomponent reactions (MCRs) have been emerged as an extremely powerful tool in combinatorial chemistry and drug discovery, since it offers significant advantages over conventional linear step syntheses, in terms to improve classical organic reactions, promote new reactions and develop straightforward synthetic routes for bioactive heterocycles.

Xanthenes and benzoxanthenes constitute an important class of biologically active heterocycles and their synthesis has been received great attention in the field of medicinal and pharmaceutical chemistry owing to their broad spectrum of pharmacological activities such as antibacterial, ${ }^{2}$ anti-inflammatory ${ }^{3}$ and antiviral. ${ }^{4}$ Some of the xanthene based compounds have found applications as antagonists for paralyzing the action of zoxalamine and in photodynamic therapy. ${ }^{5}$ In addition, their derivatives can be used as dyes, ${ }^{6} \mathrm{pH}$ sensitive fluorescent materials for the visualization of biomolecular assemblies ${ }^{7}$ and in laser technologies. $^{8}$

Among the xanthene based compounds, tetrahydrobenzo $[\alpha]$ xanthene-11-one holds an important place due to their distinctive structure and great potential for further transformations. ${ }^{9,10}$ Some novel methods for the synthesis of tetrahydrobenzo $[\alpha]$ xanthene-11-one via multicomponent condensation reaction have been reported. Several catalysts like $\mathrm{NaHSO}_{4}$. $\mathrm{SiO}_{2},{ }^{11}$ strontium triflate, ${ }^{12} \mathrm{Zr}\left(\mathrm{HSO}_{4}\right)_{4},{ }^{13}$ dodecatungustophosphoric acid (PWA), ${ }^{14}$ iodine, ${ }^{15} \mathrm{InCl}_{3} / \mathrm{P}_{2} \mathrm{O}_{5},{ }^{16} p$-toluenesulfonic $\mathrm{acid} /$ ionic liquid([bmim] $\left.\mathrm{BF}_{4}\right)^{17}$ and tetra butyl ammonium fluoride (TBAF) ${ }^{18}$ have been utilized for this transformation. However, in an era, where green methods are warranted many of these methods does not hold satisfactory as it involves the use of halogenated solvents, drastic reaction conditions, low yields and tedious work up procedure, which hampers their applications, and leaves room for further upgrading.

Development of novel synthetic methodologies to facilitate the preparation of desired molecule is an intense area of research. With this regard, efforts have been made constantly to introduce new methodologies which are efficient and more compatible with the environment. One of the most desirable approaches to address this challenge constitutes a search of surrogates for traditionally employed organic solvents which suffers from various healths and environmental concerns. ${ }^{19}$ From the view point of green chemistry, PEG-400 is found to be an interesting solvent system. It is inexpensive, thermally stable, non-volatile, non-toxic and easily degradable, has emerged as reaction medium in organic synthesis. ${ }^{20}$ In view of the emerging importance of PEG as novel reaction media, we wish to report a mild and highly efficient method for the synthesis of tetrahydrobenzo $[\alpha]$-xanthen-11-one without any catalyst.

General Experimental Procedure forSynthesis of Tetrahydrobenzo $[\alpha]$-xanthen-11-one (4a-j). To a mixture of $\beta$-naphthol 1 (1 mmol), benzaldehyde $\mathbf{2 b}(1 \mathrm{mmol})$ and dimedone $\mathbf{3}$ (1 mmol) in PEG-400 (1 mL) was heated on oil bath at $120{ }^{\circ} \mathrm{C}$ for $5-8 \mathrm{hr}$. The progress of reaction was monitored by thin layer chromatography (TLC). After completion of reaction the reaction mass was cooled to room temperature and then poured on cold water. The obtained solid was filtered, washed with water and crude solid was crystallized from ethanol to afford pure product without need of any further purification. The aqueous filtrate was distilled at $100{ }^{\circ} \mathrm{C}$ to remove water and thus separated PEG-400 was reused. The polyethylene glycol (PEG)-400 was recovered and reused without loss of activity.

\section{Results and Discussion}

We would like to report a highly efficient route for the synthesis of tetrahydrobenzo[ $\alpha]$-xanthen-11-one by using PEG400 as a greener solvent. This protocol is a one-pot three component coupling of $\beta$-naphthol, benzaldehyde and dimedone (Scheme 1) and a probable mechanism under given condition for the formation of derivatives $\mathbf{4}$ is proposed in Scheme 2 .

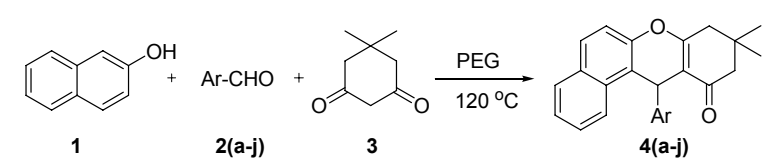

Scheme 1

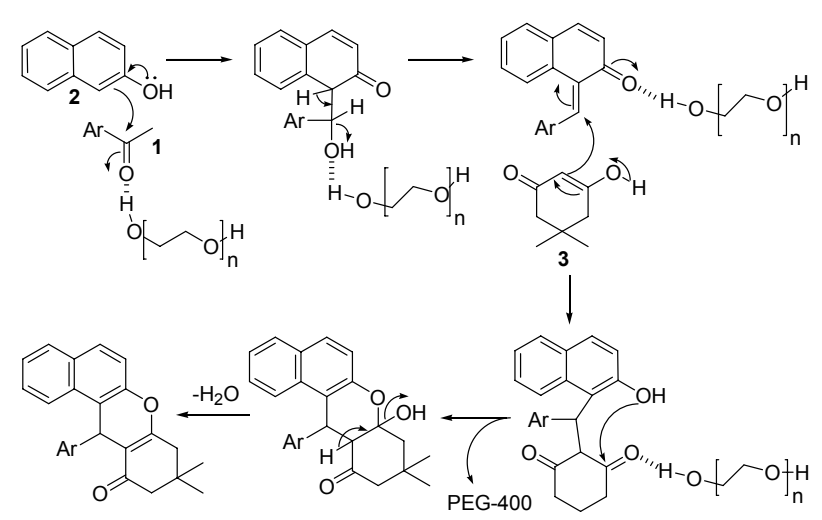

Scheme 2 
Table 1. Optimization of 4-Chloro benzaldehyde derivatives with various temperatures ${ }^{a}$

\begin{tabular}{cccc}
\hline Entry & Temperature $\left({ }^{\circ} \mathrm{C}\right)$ & Reaction Time (h.) & Yield $(\%)^{b}$ \\
\hline 1 & 25 & 20 & 3 \\
2 & 40 & 20 & 3 \\
3 & 60 & 12 & 25 \\
4 & 80 & 12 & 48 \\
5 & 100 & 10 & 67 \\
6 & 120 & 6 & 90 \\
7 & 150 & 6 & 90 \\
\hline
\end{tabular}

${ }^{a}$ Reaction conditions: $\mathbf{1}(1 \mathrm{mmol}), \mathbf{2 d}(1 \mathrm{mmol}), \mathbf{3}(1 \mathrm{mmol})$, in PEG-400 at $120{ }^{\circ} \mathrm{C} .{ }^{b}$ Isolated yields.

Table 2. Synthesis of tetrahydrobenzo[ $\alpha]$-xanthen-11-one using PEG400

\begin{tabular}{ccccccc}
\hline \multirow{2}{*}{ Entry } & \multirow{2}{*}{ Ar-CHO } & Product & \multirow{2}{*}{$\begin{array}{c}\text { Time } \\
(\mathrm{h})\end{array}$} & $\begin{array}{c}\text { Yield } \\
(\%))^{a}\end{array}$ & & \multicolumn{2}{c}{$\mathrm{mp}\left({ }^{\circ} \mathrm{C}\right)$} \\
\hline 1 & $\mathrm{C}_{6} \mathrm{H}_{5}$ & $4 \mathrm{a}$ & 6.5 & $87^{\mathrm{i}, \mathrm{ii} i \mathrm{iii}}$ & $149-150$ & $150-151^{16}$ \\
2 & $\mathrm{C}_{6} \mathrm{H}_{4} \mathrm{NO}_{2}$ & $4 \mathrm{~b}$ & 6 & 89 & $167-169$ & $169-170^{16}$ \\
3 & $\mathrm{C}_{6} \mathrm{H}_{4} \mathrm{Cl}$ & $4 \mathrm{c}$ & 6 & 86 & $179-180$ & $177-178^{16}$ \\
4 & $\mathrm{C}_{6} \mathrm{H}_{4} \mathrm{Cl}$ & $4 \mathrm{~d}$ & 6.5 & 90 & $180-182$ & $182-184^{16}$ \\
5 & $\mathrm{C}_{6} \mathrm{H}_{5} \mathrm{O}$ & $4 \mathrm{e}$ & 7.5 & 80 & $217-219$ & $219-221^{16}$ \\
6 & $\mathrm{C}_{7} \mathrm{H}_{7}$ & $4 \mathrm{f}$ & 7 & 81 & $174-176$ & $174-176^{16}$ \\
7 & $\mathrm{C}_{6} \mathrm{H}_{4} \mathrm{NO}_{2}$ & $4 \mathrm{~g}$ & 5.5 & 90 & $182-183$ & $180-181^{16}$ \\
8 & $\mathrm{C}_{6} \mathrm{H}_{7} \mathrm{O}$ & $4 \mathrm{~h}$ & 7 & 79 & $203-205$ & $205-206^{16}$ \\
9 & $\mathrm{C}_{6} \mathrm{H}_{4} \mathrm{~F}$ & $4 \mathrm{i}$ & 6. & 87 & $182-184$ & $184-186^{14}$ \\
10 & $\mathrm{C}_{6} \mathrm{H}_{5}$ & $4 \mathrm{j}$ & 6.5 & 85 & $185-187$ & $187-189^{15}$ \\
\hline
\end{tabular}

${ }^{a}$ Isolated yields. $\mathrm{i}=90 \%, \mathrm{ii}=90 \%$, iii $=88 \%$ yield after recycling.

To evaluate the effect of temperature, the reaction of a $\beta$-naphthol, 4-chloro benzaldehyde and dimedone in PEG-400 has been considered as a standard model reaction for the optimization of reaction condition. During this investigate on, efforts were mainly focused on various temperature. The effect of temperature was also studied by carrying out the model reaction in PEG-400 at different temperature. As shown in Table 1 (entries $1-2)$, the reaction did proceed but the yield obtained remained low even after longer reaction time $(20 \mathrm{hrs})$ when the reaction temperature was $25{ }^{\circ} \mathrm{C}$ or $40{ }^{\circ} \mathrm{C}$. However at elevated temperature $\left(25-140^{\circ} \mathrm{C}\right)$ using PEG-400 gave better results in terms of yield and reaction time.

Hence, the conditions of entry 6 , shown in Table 1 , were the optimized reaction conditions. Obtained results shows that at various substituents reactions gives better result, means at electron donating such as, methyl, hydroxyl, methoxy as well as electron withdrawing such as nitro, chloro and Fluoro groups works cleanly and faster. At optimized reaction conditions we done all derivatization of tetrahydrobenzo $[\alpha]$-xanthen-11-one and results were summarized in Table 2. In the present procedure, PEG400 not only acts as a phase transfer catalyst but also as a clean solvent by significantly enhancing the intramolecular cyclization. To check the reusability of medium (PEG-400) we have performed the experiment using same reactants, $\beta$-naphthol, 4-chloro benzaldehyde and dimedone in PEG-400 and we found surprising results with this medium. After three successive runs we found that there is no much more decrease in the yield of products and results of recyclability were summarized in
Table 2, entry 1.

All observed results shown that PEG-400 as an excellent medium over all reported solvents. Hence PEG-400 as efficient medium for the synthesis of tetrahydrobenzo $[\alpha]$-xanthen-11-one.

\section{Conclusions}

We have developed an alternative method by using polyethylene glycol offers a convenient, non-toxic, thermally stable, inexpensive and recyclable reaction medium for synthesis of tetrahydrobenzo $[\alpha]$-xanthen-11-one. This procedure offers several advantageous including cleaner reaction, high yields of products as well as a simple experimental and work up procedure, which makes it a useful and attractive process for the synthesis of these compounds. The recyclability of the solvent makes the development of a green strategy and the reaction economically and potentially viable for commercial application.

\section{References}

1. Tuch, A.; Walle, S. In Handbook of Combinatorial Chemistry; Nicolaou, K. C., Hanko, R., Hartwig, W., Eds.; Wiley-VCH: Weinheim, Germany, 2002, 2.

2. Hideo, T.; Teruomi, J. (Sankyo Co.) Jpn. Patent 56005480, 1981.

3. Poupelin, J. P.; Saint-Ruf, G.; Foussard-Blanpin, O.; Marcisse, G.; Uchida-Ernouf, G.; Lacroix, R. Eur. J. Med. Chem. 1978, 13, 67.

4. Lambert, R. W.; Martin, J. A.; Merrett, J. H.; parkes, K. E. B.; Thomas, G. J. PCT Int. Appl. WO9706178, 1997.

5. (a) Ion, R. M. Prog. Catal. 1997, 2, 55. (b) Ion, R. M.; Frackowiak, D.; Planner, A.; Wiktorowicz, K. Acta Biochim. Pol. 1998, 45, 833.

6. (a) Banerjee, A.; Mukherjee, A. K.; Stain. Technol. 1981, 56, 83. (b) Menchen, S. M.; Benson, S. C.; Lam, J. Y. L.; Zhen, W.; Sun, D.; Rosenblum, B. B.; Khan, S. H.; Taing, M. U.S. Patent6 2003, $583,168$.

7. Knight, C. G.; Stephens, T. Biochem. J. 1989, 258, 683.

8. (a) Siirkecioglu, O.; Talini, N.; Akar, A. J. Chem. Res. Synop. 1995, 502. (b) Ahmad, M.; King, T. A.; Ko, D.-K.; Cha, B. H.; Lee, J. J. Phys. D: Appl. Phys. 2002, 35, 1473.

9. Lesch, B.; Brase, S. Angew. Chem., Int. Ed. 2004, 43, 115.

10. Shi, Y.-L.; Shi, M. Synlett 2005, 262.

11. Das, B.; Laxminarayana, K.; Krishnaiah, M.; Srinivas, Y. Synlett 2007, 3107.

12. Li, J.; Tang, W.; Lu, L.; Su, W. Tetrahedron Lett. 2008, 49, 7117.

13. Foroughifar, N.; Mobinikhaledi, A.; Moghanian, H. Int. J. Green Nanotech. Phy. Chem. 2009, 1, 57.

14. Wang, H.-J.; Ren, X.-Q.; Zhang, Y.-Y.; Zhang, Z.-H. J. Braz. Chem. Soc. 2009, 20, 1939.

15. Wang, R.-Z.; Zhang, L.-F.; Cui, Z.-S. Synthetic Commun. 2009, 39,2101

16. Nandi, G. C.; Samai, S.; Kumar, R.; Singh, M. S. Tetrahedron 2009 , 65,7129

17. Khurana J. M.; Magoo, D. Tetrahedron Lett. 2009, 50, 4777.

18. Gao, S.; Tsai, C. H.; Yao, C.-F. Synlett 2009, 6, 949.

19. Andrade, C. K. Z.; Alves, L. M. Current Org. Chem. 2005, 9, 195.

20. (a) Das, B.; Krishnaiah, M.; Thirupathi, P.; Laxminarayana, K. Tetrahedron Lett. 2007, 48, 4263. (b) Chandrasekhar, S.; Reddy, N. R.; Sultana, S. S.; Narsihmulu, C.; Reddy, K. V. Tetrahedron 2006, 62, 338. (c) Li, J. H.; Hu, X. C.; Liang, Y.; Xie, Y. X. Tetrahedron 2006, 62, 31. (d) Wang, X. C.; Quan, Z. J.; Zhang, Z. Tetrahedron 2007, 63, 8227.

Spectroscopic data: (4d) ${ }^{1} \mathrm{H}$ NMR $\left(\mathrm{CDCl}_{3}, 200 \mathrm{MHz}\right) \delta 1.01(\mathrm{~s}$, $3 \mathrm{H}), 1.13(\mathrm{~s}, 3 \mathrm{H}), 2.32(\mathrm{~s}, 2 \mathrm{H}), 2.56(\mathrm{~s}, 2 \mathrm{H}), 5.62(\mathrm{~s}, 1 \mathrm{H}), 5.79-5.84$ (m, 2H, Ar-H), $6.61(\mathrm{~d}, 1 \mathrm{H}), 6.76-6.85(\mathrm{~m}, 2 \mathrm{H}, \mathrm{Ar}-\mathrm{H}), 7.79-7.26$ $(\mathrm{m}, 4 \mathrm{H}), 7.97(\mathrm{~d}, 1 \mathrm{H})$.; IR $\left(\mathrm{KBr}, \mathrm{cm}^{-1}\right) v 2952,1648,1597,1373$, 1231, 1184, 823; ES-MS: 389.14 (M+1), $391.13(\mathrm{M}+3)$. 